\title{
MERCADOS DE TRABALHO E HIBRIDIZAÇÃO: uniformidade e diferenças entre França e Brasil
}

\author{
LiamaCadeia * \\ Chrisian Azäis*
}

Desdearevolução keynesiana, nosanostrinta do século passado, podemos nos apoiar na interpretação de que o mercado de trabal ho é uma esfera subordinada ao nível eao ritmo daevolução da atividade econômica. Do mesmo modo, sabemos que os instrumentos de política econômica podem ser acionados para interferir nessemercado, objetivando a sustentação ou a ampliação dos níveis deemprego.

Incorporada essa interpretação na prática política de trabal hadores, sindicatos, governos e empresas, o capital ismo contemporâneo conheceu um período importante de alargamento do assalariamento, da constituição da propriedade coletiva e da consol idação da soci edade sal arial (Cf. Castel, 1995).

A partir dos anos oitenta do século passado, a correlação deforças que houvera sido cons-

* Professor-Doutor do Departamento de economia da Universidade Federal do Paraná e pesquisadora do CNPq. Praça Santos Andrade, 50 3o andar. Cep: 80000-130. Curitiba/ PR - Brasil. liana.carleial @terra.com.br

** Professor-Doutor em Economia da Universidade de Picardie Jules Verne (Amiens-França). Pesquisador no IRISES UMR 7170 Paris-FR. Université Paris Dauphine. 75775 Paris Cedex 16. christian.azais@dauphine.fr tituída anteriormentefragiliza-secom o predomínio dainterpretação li beral assentada numa visão reducionista daação da política pública, submetida aos ditames das firmas-redes mundial izadas. Elas visam a incitar a concorrência entre os Estados sociais, as políticas sociais eos trabal hadores dediferentes países, os quais precisam Ihes oferecer menores custos deprodução. A queda do muro deBerlim, em 1989, contribuiu para reforçar essa tendência.

A par disso, dá-sea ascensão decerto capitalismo rentista, apoiado na expectativa dos acionistas de rentabilidadecrescente, por um lado, e, por outro, nas transferências crescentes derenda dos países subdesenvolvidos para os países ricos, através de suas dívidas externas e pagamento de prestação de serviços tecnológicos, rendas e royalties. Paral elamente, não sepodeperder devista, ilustrando a "variedade dos capitalismos" (Hall; Solskice, 2001), o peso crescente dos fundos de pensão, deinvestimentos, os quais, tanto como as firmas multinacionais, traduzem as múltiplas facetas do capital ismo contemporâneo. O questionamento de instituições como o Fundo 
Monetário Internacional (FMI), o deslocamento do centro degravidade de boa parte da atividadeeconômicaparao LesteasiáticoeaimportânciadaChina como investidora (na África, nos Estados-Unidos, etc.), financiadora mundial esustentáculo da moe danorte-americana seconstituem em clarosindícios das mudanças pelas quais a economia mundial está passando. Em recenteartigo, ojornal Le Monde qualificou esse momento como a "Grande revanche dos países do Sul" (Le Boucher, 2007, p.26). Essas mudanças incluem ainda o lugar que passama ocupar as classes abastadas dos BRIC (Bra sil, Rússia, Índia, China) no consumo mundial.

O impacto de tamanha mudança sobre os mercados detrabal ho ainda não ésuficientemente claro. Em primeiro lugar, há uma espécie de uniformização aparente deresultados, uma vez quea natureza dos contratos de trabal ho al terou-se, especialmente na Europa Ocidental, na direção de uma multiplicidadedemodal idades deformas de contratos detrabal ho. Essatendência, paraal guns, significariauma aproximação desses mercados dos mercados latino-americanos, estrutural mentefrá geise prisioneiros da heterogeneidadeestrutural .

Em segundo lugar, ao longo detoda a crise ainda em vigência nos mercados de trabalho, a participação dos trabal hadores assalariados, subordinados e dependentes de um patrão, crescenos países desenvolvidos, confirmando a máxima de queé o assal ariamento a forma preval ente de inserção nos mercados de trabal ho contemporâneos. Nos países subdesenvolvidos, mesmo os devedores e com baixo crescimento entre os emergentes, como éo caso brasileiro, o número detrabal hadores com carteira detrabal ho assinada tem crescido. ${ }^{1}$ Essa semel hança nos permitedizer que os impactos sobre os mercados de trabalho são comparáveis entreo Nortee o Sul?

Em terceirolugar, há outra uniformidade, decorrente do fato de que as medidas de flexibilização impostas pelos organismos multilaterais geraramas mesmastendências deajustesnos

${ }^{1}$ No Brasil, a carteira assinada pelo empregador é, para o trabal hador, a garantia de acesso aos direitos trabal histas previstos na legislação em vigor no país. mercados detrabal ho do Nortee do Sul, mas não o mesmo cronograma² enemas mesmas conseqüências. ${ }^{3}$ Assim, a natureza dos contratos detrabaIho alterou-se, especialmentena Europa Ocidental, concretizando a troca entre os contratos por tempo indeterminado (CDI) por aqueles detempo determi nado (CDD), ou reagrupados na denominação de "formas particulares deemprego" (Barbier, 2002), ou então por CDI parciais. No Brasil, desde 1994, com o fim da política salarial no Governo FHC, inicia-se um processo de busca pela "flexibilização" deum mercado detrabal ho jáestrutural menteflexível equenão havia ai ndaconstituído um real estatuto para o trabal ho. Será possível apontar uma tendênciaà "brasilinização" dos mercados detrabal ho europeus, ou atédo Ocidente (Guimarães, 2007)?

Em quarto lugar, os países subdesenvolvidos sofrem um processo demaior fragilização, pois, nacorrida por atrair investimentos diretos estrangeiros, é preciso mostrar-se competitivo e, quem sabe, reduzir mais ainda os poucos direitos sociais arduamenteconseguidos. Para ondecaminham então os mercados detrabal ho latino-americanos?

Esse artigo se propõe a responder a tais questões, col ocando no centro da discussão o conceito dehibridização (Azaïs, 2003), como categoria capaz de capturar as diferentes formas de flexibilização vivenciadas pelos mercados detrabal ho econstruir uma comparação sobreo desempenho recentedos mercados detrabal ho na França e no Brasil. Comparações internacionais são difíceis ecomplexas, mas imprescindíveis parao avanço de uma mel hor compreensão dos mercados detrabal ho contemporâneos.

O conceito dehi bridização auxiliarána de fesa da hipótese dequeapenas aparentemente, são

2 Tal fato se deve à especificidade de cada país, de sua correl ação de forças interna - o que remete a questão da governança e às modal idades diferenciadas de inserção na gl obalização.

${ }^{3}$ As práticas de flexibilização dos mercados de trabalho variaram entre os países e não tiveram um mesmo cronograma. Em geral, podem ser incluídas nesse rol: cortes nos direitos trabal histas, afrouxamento do marco legal de regulação do mercado de trabal ho, redução dos salários, maior facilidade no desligamento de trabal hadores, substituição dos contratos de trabalho por contratos comerciais, subcontratações e terceirizações etc. 
comparáveis os resultados obtidos no Norte e no Sul. Na realidade, na França, como de resto na Europa, a conjugação deformas diferentes decontratos detrabal ho, embaçando lige ramenteas fronteiras entretrabal ho subordinado eindependente, écompatível comoal argamento do assal ariamento ecom a permanência de valores sól idos quanto à necessidadedemanutenção deum Estado Social.

NoBrasil, a hi bridização assumeoutra natureza, uma vez quea participação do trabal ho informal foi estrutural mentede $40 \%$ dosocupados, oque significaquea sociedadesempreconviveu politicamente com a exclusão e "o não acesso" a direitos sociais degrandepartedesua população ocupada.

Masa uniformização entreos dois mundos nos parece dada apenas pela tendência de assal ariamento no Norteeno Sul, como confirmação do avanço do capitalismo. A associação entre mercados debensedetrabal ho permiteevidenciar que as possi bilidades de geração de postos de trabal ho, no Norte e no Sul, são regidas por regras distintas, sejuntarmosa essa discussão a natureza da estrutura produtiva dos países desenvolvidos versus a dos países subdesenvolvidos. Nesseúltimo caso, dadaa atual inserção do Brasil numa economia mundial izada, regi da pel o endividamento externo, com moeda frági i ${ }^{4}$ esem poder decompra sobre as mudanças tecnol ógi cas em curso, o raio demanobrapara criar ocupaçõesqual ificadas, com melhor padrão de remuneração, é praticamente nulo. Associarse a essa dificuldade estrutural a ausência deumasociedadesuficientementeorganizada para exigir políticas sociais de Estado (e não deGovernos), assentadas numa matriz dedireitos. Tal quadro marca a natureza radical mente distinta das configurações dos mercados detrabaIho no Norte e no Sul.

Para responder aos pontos aqui anunciados, o artigo está estruturado em cinco partes. $\mathrm{Na}$ primeira del as, fazemos uma anál ise da natureza dagl obal ização, as implicações dessa fase do capital ismo sobreas interpretações do desenvol vimento econômico contemporâneo; discutimos tambémos

${ }^{4}$ Embora muito valorizada nos últimos anos. efeitos diferenciados sobre os países desenvolvidos (Norte) esubdesenvolvidos (Sul) e, ainda, os efeitos sobre os mercados de trabal ho, num momento deforteassimetria entreas forças do capital e do trabalho. Na segunda parte, discutimos a especificidadedo mercado detrabal ho, bem como as condições sociopolíticas de sua regulacão, as quais, nos países europeus, engendrarama sociedadesalarial à la Castel, ausenteno Sul. Na terceira parte, introduzimos ediscutimos o conceito de hibridização (Azaïs, 2003, 2006) que captura os efeitos da flexibilização e da precarização d(n)os mercados detrabal ho. Na quarta parte, associamos mercados detrabal ho ehibridização, para evidenciar que a uniformi dade de mercado de trabal ho queexisteentre o Nortee o Sul, ou, mais precisamente, entreaFrança eo Brasil, éconfigurada pela prevalência do assal ariamento como forma dominantedeinserção nos mercados detrabal ho, mesmo queempatamaresbem distintos. A hibridização encontrada nos mercados de trabalho dos dois países, porém, é de natureza, volumee conseqüências distintas. Na realidade, o que predomina entre esses mercados de trabal ho é a diferenciação. A marcamai or detal diferenciação éconferida pela regulação da economia brasileira e de seu mercado detrabal ho. Essa regulação sempreestevesujeita a crises, engendradas pelo lugar do país na divisão internacional dotrabal hoe, internamente, por uma sociedade profundamente desigual, atravessada por forte concentração derendaeprofundas dificuldades em sua representação política. Essa regulação particular é responsável pela não constituição deuma sociedadesal arial noBra sil, o que, por si só, descarta a possibilidade de falar-se com precisão de uma "brasi linização" do Norte. Diferentes são, também, as perspectivas de mercados detrabal ho no Nortee no Sul.

GLOBALIZAÇÃO E MERCADOS DE TRABALHO

As anál ises sobrea gl obal ização acarretaram al gumas perturbações no campo das ciências sociais, nesses últimos anos, principalmente no que 
tangeà apreciação das teorias sobre o desenvolvimento. Com efeito, enquanto a economia ou a sociologiado desenvolvimento seapresentaram como asúnicas abordagens capazes detratar as questões ligadas ao desenvol vimento, percebendo-o como "atraso" (Rostow, 1960), ou remetendo a lógicas diversas dedesenvolvimento, diretamentevinculadas ao avanço do capital ismo (Amin, 1973; Cardoso; Fal etto, 1970; Palloix, 1987), hojeem dia, os estudos sobrea gl obal ização têm outrafeição. Isso se deve ao fato de que procedem de uma abordagem gl obal, sem, no entanto, centrarem suas preocupações unicamentesobreo Estado, mas levando em containstituições quepertencem a diversas escalas. De fato, enquanto a problemática do (sub)desenvol vimento lembra prioritariamenteos países do Sul, a globalização tem o mérito de posicionar os questionamentos no conjunto das relações entre as nações e no seio de cada nação. Elacontorna ou col oca demaneira diferenteaquestão do lugar do Estado-nação e de seu papel no concerto das nações.

As abordagens sobreo desenvol vimento são de três ordens. Umas, qualificadas de in situ, insistemnaesfera local edão lugar a uma infinidade deestudos decaso (proliferação deanál ises sobre os clusters, por exemplo), nos países em desenvolvimento, geral mentedesconectadas daesferainternacional . Nomesmoveio, análises sobreaintegração dos países do leste europeu à União Européia fazemreferênciaà economia datransição.

Outras oscilam entreas preconizações das instituiçõesinternacionais-Banco Mundial eFMI, principalmente- eas inúmeras ações etrabal hos dos "práticos" do desenvol vimento, dentreosquais sedestacam as Organizações não Governamentais (ONGs).

Os pontos de convergência entre as duas primei ras abordagens são quase inexistentes. No seio das instituições internacionais, o discurso não éunânime, e há vozes destoantes sobre o fundamento da aplicação de remédios idênticos aos "males" supostos ou reais dos países em apreço. Outrossim, a multiplicação das ações parece não ter produzido ainda um discurso claro sobre o desenvolvimento.

Um terceiro nível de análise concerne ao interesse despertado pela emergência de novas potências industriais, como o Brasil, a Rússia, a Índia e a China - os BRICs - e o questionamento que ela acarreta para a ordem mundial, gerando processos de deslocamento das indústrias do Norte para o Sul, com conseqüências para o mercado de trabal ho, fenômenos usados para justificar desregulações nos países do Norte e a condução depolíticas protecionistas.

A gl obal ização não é um fenômeno novo, porém entrou numa nova fase, caracterizada por traços acentuados de financiarização, do caráter rentista do capitalismo, da reestruturação tecnológica e produtiva, assim como da presença da firma-redecomo formato organizacional dominante. Coma gl obal ização, instaurou-se uma divisão internacional do trabal ho particular, regi da pelo acirramento da concorrênciaquedeslocalizaindústrias eatividades deserviço.

Nessa fase, a gl obal ização levou a um tipo de hierarquização do mundo a partir da moedae do conhecimento ou, mai s especificamente, através do acesso ao desenvolvimento da capacidade tecnológica, da capacidade de inovar e, por fim, da capacidade devender o direito de uso. Outrossim, o capital-moeda sob a forma de uma moeda hegemônica, o dólar estadunidense, éa condição prévia e o resultado detodas as economias nacionais (Oliveira, 2005). ${ }^{5}$

Nessa hierarquização, o Nortee o Sul ocupam postos bem diferentes. Ao mesmo tempo, pareceóbvio que, no conjunto do mundo subdesenvolvido, existem também diferenças e hierarquizações: aĺndia ea China, ao contrário da América Latina, por exemplo, ocupamlugares di-

\footnotetext{
${ }^{5}$ Quando este artigo foi concluído, em junho de 2007, a fragilização da moeda americana não estava ainda tão evidente como no momento de sua entrega para publicação, em novembro de 2007. A evolução do quadro americano exige uma ponderação, mas não o abandono do argumento presente no corpo deste artigo. Mesmo que o portfól io de al guns países venha incorporando, de mais a mais o euro, seria necesario que China e Índia redirecionassem amplamente as suas aplicações, forçando a queda da moeda americana. Enquanto isso não acontece, essa ponderação nos permite manter o argumento central presente no artigo.
} 
ferenciados, tendentesasetornarem hegemônicos. Cada lugar é, a nosso ver, definido pela relação quecada país ou região mantém comaglobal ização.

Paral elamente, uma verdadeira mudança se produziu na re lação cada vez mais conflituosaentre públicoeprivado, nosentido deumquestionamento das funções do Estado, seja pel a presença de novos atores (ONGs, por exemplo), seja pela redefinição puraesimples do lugar do Estadonesse processo, manifestado, por exemplo, na proliferação deparcerias público-privadas. Essa mudança seexplica demanei ra simples: a gl obalização não supõe o fim do Estado; ao contrário, precisa dele.

No mundo subdesenvolvido, o Estado se tornou um agente poderoso da global ização, na medidaqueele produz as desregulamentações dos mercados (principal mentea dos mercados detrabal ho efinanceiro) eage como uma plataformafinanceira quando titulariza a sua dívidaeatrai investimentos diretos estrangeiros (IDEs ${ }^{6}$ ).

Nessecontexto, os mercados detrabal hotêm sofrido um verdadei ro ataque dos governos nacionais, na tentativa deflexi bilizá-los, flexibilização entendida como um conjunto denovas regras que buscam reduzir o custo do trabal ho, esquecendo quesalário tambémédemanda; buscam também trabal ho esalário, substituindo aremuneração por participação nos lucros, eimpor novas regras na reduzir os di reitos trabal histas existentes, separar

regulamentação do tempo detrabal ho. Enfim, salários epolíticasocial tornam-sevariáveis deajustenum mundo gl obalizado.

O resultado de vinte anos de ataque aos mercados detrabal ho transparecena Tabela 1 . No período que se inicia nos anos setenta do século XX atéo ano 2004, a participação dos salários no PIB cai consistentemente, à medida que a mundial ização avança. Essa perda éimportante, pois, no período entre 1981 e2004, ela atinge 10,4 pontos percentuais para a França e 8,6 pontos percentuais paraa Europa dos Quinze.

No caso brasileiro, a participação dos salários no PIB, em 2003, era de $35 \%$, quando jáhavia sido 44\% nos anos 1970. Ou seja, num quadro de subdesenvol vimento, a participação salarial no PIB tendea ser estrutural mentemenor, reduzindo-se mais ai nda na presença de uma correl ação deforças políticas muito favorável ao capital .

O ataqueaos mercados detrabal ho, no entanto, anunciava que a flexibilização teria o condão de criar empregos, uma vez que as taxas de desemprego ampliavam-seconsistentementeapós a crise desencadeada pel o aumento dos preços do petróleo em 1973. Desse modo, ao contrário da interpretação keynesiana, queindicava a necessidade de ol har para al ém do mercado de trabal ho para compreender o seu funcionamento, o receituário liberal propunha uma solução a partir priTabela 1 - Participação dos salários em \% do PIB

\begin{tabular}{lcccccc}
\hline \multicolumn{1}{c}{ Países } & Anos 1970 & $\mathbf{1 9 8 1}$ & Anos 1980 & Anos 1990 & $\mathbf{2 0 0 4}$ \\
\hline EUA & 70,0 & 69,4 & 68,7 & 67,5 & 66,5 \\
\hline EU dos 15 & 74,2 & 75,3 & 71,5 & 68,4 & 66,7 \\
\hline França & 73,6 & 76,4 & 71,6 & 67,1 & 66,0 \\
\hline Alemanha & 72,2 & 73,1 & 69,5 & 66,4 & 64,2 \\
\hline Reino-Unido & 75,0 & 73,9 & 74,4 & 73,7 & 73,9 \\
\hline Itália & 72,2 & 71,7 & 69,9 & 64,6 & 61,6 \\
\hline Fonte: Comissão Européia apud Plihon (Cf. 2006, p.130) \\
Nota: A participação salarial está corrigida pela taxa de assalariamento
\end{tabular}
mordialmentedopróprio mercado de trabalho. A suposta base desustentação para esse argumento estariana "rigidez" do mercado de trabalho, especialmenteo europeu, quando comparado ao flexível mercado detrabal ho da América do Norte. Sem surpresas, é possível comprovar queo re médio não levou à cura do

${ }^{6}$ Atilio Borón (Cf. 2004), muito justamente, chama a atenção para a mudança de sentido da pal avra reforma. Na tradição do pensamento político ocidental , a reforma esteve associada a mudanças graduais em direção a uma mai or igual dade e liberdade do conjunto da população; as "reformas" implementadas nas últimas décadas ná América Latina são cruéis "contra-reformas", levando a processos de involução social. problema.

A Tabela2, a seguir, mostraquea capacidadedegeração deemprego, nos EUA, éatual mente tão limitadaquantoa européia. Mostraaindaquea capacidade de criação de empregos caiu após o 
Governo Reagan, contrariamenteao quese procura divulgar. No caso europeu, considerando a diversidade das políticas sociais implementadas ea manutenção do Estado-Providência, essa capacidade cresceu no mesmo período. Deacordo com Vergara (2006, p.89) "entre maio de 1997 e maio de2006, os EUA criaram 14,5 mil hões deempregos líquidos enquanto a Europa dos quinze criou 16,3 milhões". Assim, nãoéevidentearelação entre rigidez versusflexibilidadedalegisl açãotrabal histae criação deempregos. ${ }^{7}$

Tabela 2 - Crescimento do emprego nos Estados Unidos e na Europa (em \% anual)

\begin{tabular}{lcccc}
\hline País/Grupo de países & $\mathbf{1 9 7 7 - 1 9 8 6}$ & $\mathbf{1 9 8 7 - 1 9 9 6}$ & $\mathbf{1 9 9 7 - 2 0 0 6}$ \\
\hline Estados Unidos & 1,9 & 1,4 & 1,2 \\
\hline EU dos 15 & 0,2 & 0,5 & 1,2 \\
\hline Zona euro* & 0,2 & 0,6 & 1,2
\end{tabular}

Fonte: EUROSTAT, Ameco Database, US Bureau of Labor Statistics, apud

Vergara (2006, p.89)

* Europa dos 15 sem o Reino-Unido, a Dinamarca e a Suécia.

Emcompensação, épreciso reconhecer que os mercados de trabalho, na França e no Brasil, sempreforam sensivelmentediferentes. Na França, o acordo sobre a construção histórica de uma sociedadesal arial repousou, erepousa ainda, sobre uma relação entre trabal ho e proteção social muito sól ida, mesmo nessa fase da gl obal ização.

No Brasil, o quadroédiferente. Em primeiro lugar, a estruturação do capital ismo tardio no Sul revel ou-seincapaz deconstituir o mercado de trabal ho como meio de integração social para o conjunto dos trabal hadores, mesmo diantedocrescimento do assal ariamento. Emsegundolugar, essa estruturação do capitalismo não permitiu tampouco associar a esseassal ariamento uma construção decoletivos esindicatos representativos da grande maioria dos trabal hadores. Em terceirolugar, a apropriação privada do Estado e dos fundos públicos impediu a construção de uma propriedadesocial à la Castel. Enfim, nuncafoi possível consolidar um verdadeiro estatuto para o trabal ho.

\footnotetext{
7 Mesmo a OCDE, no seu relatório de 2004, acaba reconhecendo que não é possível identificar, nas reformas estruturais dos mercados de trabalho, efeitos positivos
} sobre o emprego.
Entretanto, esse quadro acima descrito é compatível com a existência de um aparato institucional querege parcela do mercado detrabal ho, ou seja, os trabal hadores registrados ou formais. Em 1988, a Constituição criou um fundo coletivo- oFundo deAmparo ao Trabalhador (FAT) -, com recursos do Estado, com o intuito deconstituí-lo como base desustentação financeira paraa política pública de emprego, que ganhou, assim, umfinanciador estável.

Na realidade, a anál ise do desempenho econômico dessas duasúltimas décadas da economia brasileiraexigeal guns cui dados. Os anos noventa do sécul o passado foram marcados pela intensificação da abertura comercial , pel os processos de reestruturação produtiva, subcontratação e implementação de planos deestabilização queredundaram na criação de uma nova moeda: o real . Assim, o projeto completo das reformas era assim composto: controle da inflação; abertura comercial, como objetivo deampliação da competitividade; privatização das grandesempresas governamentais; desregulamentação financeira edos mercados de trabalho; controle dos gastos públicos, com a redução do papel do Estado; efortediferencial entre a taxa dejuros interna eexterna.

Além disso, a utilização da âncora cambial, quesobrevalorizou amoeda nacional, permitiu um fortemovimento expansionista das importações, centrado em bens decapital eintermediários, cujos resultados foram a ampliação dos componentes importados na produção nacional e, ai nda, a racional ização dos processos produtivos, ambos com efeitos danosos sobre o emprego. Esse "pacote" redundou num model o de crescimento errático, caracterizado pelo stop and go. A téa desval oriação do real, ocorrida em 1999, os efei tos sobre o mercado detrabal ho foram desastrosos, com o crescimento do desemprego eda informal idade.

A partir desse momento, no entanto, com o mesmoarsenal macroeconômico, masnumaconjunturainternacional maisfavoráve, aindaerraticamente, o desempenhodoPIB melhora, iniciando-seumprocesso de reversão dos efeitos danosos vividos pelo mercado detrabal ho. A partir do Governo Lula, em 
2003, a matriz macroeconômica permanecea mesma, mas, o processo lento de queda da taxa de juros (SELIC), associado tambémà queda da taxa dejuros delongo prazo, empregada pel oBNDES, num cenário internacional favorável, vão tornar mais visíveis os efeitos positivos sobre o mercado de trabal ho. Associem-se ainda as medidas implementadas de ampliação do crédito pessoal consignadoe do Programa Bolsafamília, queatinge, hoje, 11 milhões defamílias, contribuindo para ampliar a basedegastosfamiliar.

A Tabela 3 indica que, no exemplo brasileiro, a partir de 2003, o desempenho do PIB émais promissor, com taxas decrescimento ainda baixas em rel ação àsnecessi dades do seu desenvol vimento, porém, superiores àquel as do período anterior. Esse comportamento tem impactos muito positivos sobre o crescimento da ocupação e, em particular, sobre o crescimento do emprego assal ariado. Esse é o quadro geral da relação entre gl obal ização emercado de trabal ho na Françaeno Brasi l. Na seção seguinte, discutiremos os conceitos básicos que dão sustentação à análise aqui em desenvolvimento. cimento do investimento edaacumulação, proposições devidas a Keynes e a Marx. No entanto, a mais real ista está presentenão apenas entreesses autores citados, mas também no paradigma daeconomia política clássica, queéo caráter subordinado dos trabal hadores às decisões dos capitalistas, ou seja, a assimetria na correl ação de forças entre capital e trabalho. Assim, não há uma oferta de trabal ho independente da demanda por trabal ho. Nesse ponto, também concordavam Smith e Ricardo.

Keynes, posteriormente, ao afirmar queo capitalismo entregue meramente às racionalidades privadas poderialevar aumagrandeirracionalidade, como aquela vivida durante a Grande Depressão, vai sinalizar aimperiosa necessidadeda constituição da esfera pública eda incorporação do Estado naeconomia deforma mais decisiva.

A constituição da esfera pública vai acabar por exigir a publicização das regras contratuais, deixando as decisões deserem tomadas meramenteentreentes privados. Assim, équea publicização dos contratos de trabal ho passa a ser regra, assume-sea assimetria entrecapital etrabal ho, identificando-se a necessidade de proteção aos trabal hadores. Logo, os conTabela 3 - PIB versus ocupação/emprego - Taxas de variação

\begin{tabular}{|c|c|c|c|c|c|c|}
\hline & 2001 & 2002 & 2003 & 2004 & 2005 & 2006 \\
\hline Var. PIB & 1,3 & 2,7 & 1,2 & 5,7 & 2,9 & 3,7 \\
\hline Var. ocupação & & 4,6 & 1,5 & 5,5 & 3,1 & 2,4 \\
\hline Var. emprego assalariado ${ }^{1}$ & & 4,7 & 1,8 & 7,1 & 2,9 & 4,2 \\
\hline
\end{tabular}
tratos de trabal ho retratam uma "dada" divisão de riscos entrecapital etrabal ho. Esta éa base da constituição de desenvol vimento do direito do trabal ho no mundo contemporâneo.

O caminho construído histó-

\section{A ESPECIFICIDADE DOS MERCADOS DE TRABALHO}

O mercado detrabal ho tem especificidades próprias, eateoriaeconômica foi muito efetivaem remarcar esse ponto desde as suas primeiras elaborações. À exceção da teoria marginalista, em todas as demai s contribuições essemercado étratado de forma a incorporar tais especificidades. A mais importante delas, sem dúvida, é a sua dependência do mercado debens, dos ritmos do cres- ricaepoliticamenteparafazer facea essa assimetria foi a organização dos trabal hadores em sindicatos e partidos políticos. Não é sem razão que o conjunto demedi das preconizadas pelo Consenso de Washington, ao promover aflexibilização dos contratos detrabal ho, redunda exatamentenuma perdasignificativa da participação dos salários no PIB decada país, como indicado na Tabela 1.

A vigência das práticas políticas oriundas do consenso de Washington, confusamente intituladas deneol iberais, mas certamenteinformadas pela teoria marginalista, tem procurado 
entronizar os mercados como a única referência do capital ismo. Conseqüentemente, tem atribuído aos mercados de trabal ho um enorme poder ou capacidade deajuste, através de sua fl exi bilização (de salários, dos contratos e do tempo de trabaIho), insistindo em reeditar o período prékeynesiano, no qual os ajustes de salário, ou a não-interferência do Estado e dos sindicatos, supostamenteseriam capazes de reconduzir o mercado de trabal ho a uma posição de equilíbrio com pleno emprego. Essa tem se mostrado uma alternativa fal sa, como as seções anteriores já indicaram. Na reali dade, a recuperação do emprego depende mais deações fora do mercado detrabal ho do que nel e mesmo. Para compreendermos meIhor as diferenças demercado de trabal ho entreo Norteeo Sul, épreciso ainda considerar-seo conceito desociedadesal arial.

\section{A constituição da sociedade salarial}

O conceito de sociedade sal arial proposto por Castel (1995) tem um estatuto diferenciado da "relação salarial ${ }^{8 "}$ fordista, própria à Escola da Regulação francesa. Elefaz uma mol dagem entre históriaeeconomia etem umaabrangência maior.

A idéia de sociedade salarial parte da própria concepção de indivíduo, o qual, através da venda de sua força de trabal ho, selivra das sujeições locais, das tradições e dos costumes. Já as mul heres selivram da reclusão doméstica através do trabal ho, vendido na esfera pública. Nesseconceito, otrabal hotemuma concepção libertária, que é herdeira da tradição de Smith (Carleial, 1992). Entretanto, exige-se que cada trabal hador tenha uma inscrição no coletivo dos trabal hadores. O salário mínimo simboliza a porta de entrada no mercado detrabal ho, a partir daqual abre-seuma gama deposições extremamentediferentes quanto ao salário, ao reconhecimento social, ao interesse pelo trabal ho, ao prestígio, etc..

${ }^{8} \mathrm{~A}$ tradução francesa de "relação sal arial", no caso da interpretação da Escola da Regulação, é "rapport salarial".
O autor argumentaquesempretivemosuma dadarelação sal arial ao longo do desenvolvimento capitalista. A revolução industrial antecipa a presença deumarelação salarial moderna. Para Castel (1995, p.326), no capitalismo, a relação salarial podeassumir configurações diferentes, eéimportantelocal izar as transformações quecomandama passagem de uma forma a outra. Nesse sentido, para a passagem da relação preval ecenteno início da industrialização à relação salarial fordista, é preciso reunir as cinco condições seguintes:

- Uma firmeseparação entreos quetrabal ham efetiva eregularmentee os inativos ou os semi-ativos, portanto uma defi ni ção precisa de população economi camenteativa. Nestecaso, épossível definir elocal izar os ocupados, os quenão o são, os trabal hadores regulares eos intermitentes, os remunerados eos não remunerados, etc. (p.327).

- A fixação do trabal hador a seu posto detrabal ho e a racionalização do processo de trabal ho no quadro deuma gestão do tempo precisa eregulamentada(p.331).

- O acesso, através do salário, a novas normas de consumo operário, através das quais cada traba Ihador torna-se consumidor da produção em massa (p.334).

- O acesso à propriedade social e aos serviços públicos (bens coletivos), pois assim otrabalha dor torna-se usuário e partici pante do estoque de bens comuns disponíveis na sociedade (p.337).

- A inscrição de um direito do trabal ho quereconhece otrabal hador como membro de um coletivo dotado deestatuto social, al ém da dimensão puramente individual do contrato de trabal ho (p.338).

Tanto a relação salarial como a sociedade salarial refletem o capital ismo como dominância do trabal ho assalariado, sem referência a outras formas de trabal ho sob o capital. A interpretação de Castel é general izante, na medida em que faz menção a uma sociedade detrabal hadores assalariados submetidos a certas regras de organização. Castel trata de sociedades que constituíram um 
mercado detrabal ho, engendrarama generalização do assalariamento, construíram canais departicipação política, sindicatose organizações dasociedade civil em geral, consol idaram as suas democracias e toda uma infra-estrutura política, institucional ejurídica que reconhecea condição do trabal hador assal ariado. Exempl os são as sociedades européias, mesmo quecom diferenças entreelas. O mesmo não podemos dizer dos EUA e dos chamados países subdesenvolvidos ou em desenvolvimento.

A sociedadesal arial explicitao conflito entre capital etrabal ho, reconheceadiversidadedostrabal hadores assal ariados numa mesma sociedadee sinaliza para as diferenças históricas, sociaise políticas entreas sociedades capital istas contemporâneas. Além disto, traz o Estado para o centro da discussão da relação entrecapital etrabal ho, outro indicador das diferenças entreos distintos países.

Para as sociedades que construíram sociedades salariais, é factível incorporar a análise de Oliveira (Cf. 1988) sobreo surgimento do anti-vaIor ea desmercantilização da força de trabal ho, à medida que os trabal hadores passaram a ter direito não só ao salário direto, mas também ao "salário indireto", ${ }^{9}$ expresso no acesso a educação, saúde, transporte, auxílios para escolaridadedos filhos, moradia subsidiada etc. Ainda à luz dessa interpretação deOliveira, a obtenção dessas mercadorias fora dos mercados indica uma forte e exitosa regulação social sobre os mercados. Assim, uma vez que o fundo público épressuposto da acumulação, atendebdo tanto ao capital como ao trabaIho, a luta declasses contemporânea transfere-se para a luta por sua apropriação. Nesse sentido, o conjunto deregras preconizadas pelo consenso de Washington para o avanço do capital ismo ataca de forma viol enta essa construção e investena dire ção dare-mercantil ização daforça de trabal ho (visível, inclusive, nos países desenvolvidos, natendência a fazer dos contratos detrabal ho contratos

\footnotetext{
9 Embora tal denominação seja sujeita a controvérsias, simplesmente pel o fato de que quem diz salário diz obrigações, o que não está i mbuído na asserção "salário indi-
} reto". detipo comercial), com efeitos diferenciados entre os mundos desenvolvido esubdesenvolvido, para a al egria dos seguidores de Hayek.

Entendemos, então, que a análise da regulação diferenciada dos mercados detrabal ho no Norte e no Sul pode ser compreendida mediante o acompanhamento do grau de desmercantilização ou remercantilização da força detrabal ho que cada uma das soci edades atingiu ao longo de seu desenvolvimento, ou ainda, da solidez ou fragilidade, ou inexistência desuas sociedadessalariais.

Em seguida, introduziremos o conceito de hibridização, como concei to capaz de capturar o processo deflexibilização ao qual estão submetidos os mercados de trabal ho no Nortee no Sul.

\section{HIBRIDIZAÇÃO}

Vista sob o ângul o das formas de inserção no trabal ho, a hibridização se traduz por um semnúmero de termos, destinados a ilustrar a pluralidade das situações. A hibridização, como marcador da evolução das sociedades salariais, questiona a inserção dos indivíduos nos mercados de trabal ho. Ela seexpressa através do entrelaçamento deformas de inserção no trabal ho, visíveis na proliferação dos contratos detrabal ho, que correspondem a arranjosinstitucionais di versose nos quais os indivíduos estão engajados pessoalmente-podendo um trabal hador ser detentor de mais deum contrato detrabal ho. Elatestemunha uma novarelação para com otrabal ho, inscritapara a maioria dos indivíduos no assal ariamento.

A hibridização é consubstancial da multiplicação dos contratos detrabal ho. "Opor umtrabal ho dependentea um trabal ho independenteé totalmenteinsuficienteparacaptar amultiplicidade ea complexidade das formas deinserção no traba Iho" (Azaïs, 2006). Tal constatação sublinha a pluralidade dos contratos de trabal ho eparticipa decertaimprecisão jurídica na qual os indi víduos em si tuação detrabal ho estão engajados. Essefe nômeno tende a perturbar duas idéias de Castel: 
uma, segundo a qual "somente o indivíduo éresponsável e titular de direitos sociais"; outra que defende a idéia de que num quadro de trabal ho instável, convém “conciliar mobilidadeeproteções, dando ao trabal hador móvel um verdadeiro estatuto" (Castel, 2003, p.84).

Esseprocesso tomamúltiplasfeições segundo a perspectiva seja do Norteou do Sul , em razão da presença mais ou menos forte de um EstadoProvidência, cujas regras de funcionamento não são as mesmas em todos os lugares.

A hibridização será examinada através da análisedesituações aparentementesemel hantes na França eno Brasil. Contudo, as diferenças dastra jetórias recentes desses dois países ilustrarão, ao mesmo tempo, o fenômeno de extensão do assal ariamento epermitirão quesetomememconta as regulações em ambos os teatros deoperações. Essas regul ações são o fruto do agenciamento das forças internas e dão uma percepção di ferenciada - porquecontextualizada- da gl obalização.

$\mathrm{NaFrança,} \mathrm{a} \mathrm{multiplicação} \mathrm{dos} \mathrm{contratos} \mathrm{de}$ trabalho é perceptível na coabitação dentro das empresas deassalariados, quepertencemaordens diversas - trabal hadores em CDD, CDI por tempo integral, tempo parcial, precários, temporários, dependentes degroupements d'employeurs ${ }^{10}$ ("agrupamentos de empregadores"), de sociedades de portage, ${ }^{11}$ etc.. Da mesma forma, os contratos podemser mercantis, não mercantis ou mistos. Uns são regi dos pelo Código do Trabal ho, outros não. São exercidos sob diferentes modalidades, emter-

$10 \mathrm{O}$ agrupamento de empregadores permite às empresas se reagruparem para empregar uma mão-de-obra que não poderiam sozinhas recrutar. Trata-se de uma das formas de exercício da pluriatividade: os assal ariados do agrupamento de empregadores efetuam períodos de trabalho sucessivos junto a cada uma das empresas aderentes ao agrupamento(http://www.travail.gouv.fr/informationspratiques/fiches-pratiques/embauche/embauche-par-ungroupement-employeurs-975.html).

${ }^{11} \mathrm{~A}$ "portage" representa o enquadramento contratual da rel ação tripartite entre uma pessoa que fornece um trabal ho pontual (missão), denominada o "porté"; a "sociedade de portage" que o acol he e garante a gestão administrativa e contábil da contratação e da missão (declarações junto aos organismos de Previdência, gestão do pagamento, estabelecimento dos holerites, redação do contrato de prestador de serviços negociado pelo porté, estabel ecimento e das notas fiscais, etc.) e uma empresa - "o cliente"- para a qual o porté fornece um trabalho especializado. mos de tempo - tempo integral, tempo parcial -, de duração - CDI, CDD, temporário ${ }^{12}$ - ou de lugar deseu exercício - al ternância em empresa, escola, universidade, em casa -, no caso de tel etrabal hadores ou denovas profissões. ${ }^{13}$

Além do mais, ahibridização ésel etiva. Ela se polariza em certas categorias - jovens, mulheres, não qualificado(a)s, pessoas idosas (para o mercado detrabal ho) - quesuportam mais do que o(a) outro(a)s osriscos do desemprego. Encontramseaí os principais destinatários dos contratos subsidiados, por tempo parcial ou deínterim. Assim, a ancoragemna precariedadetorna-seumfenômeno cada vez mais recorrente: em 2003, entre 8 e $10 \%$ dos ativos conheciam, há três anos ou mais, uma situação de desemprego ou de emprego precário (Ires, 2005, p.15).

Na realidade, o Brasil não conseguiu constituir uma sociedade sal arial , e suas forças políticas não foram capazes deinstaurar um Estado-Providência nos mol des europeus, que constituísse um sistema efetivo de proteção ao conjunto dos trabal hadores. O momento mais próximo à constituição de um Estado-Providência queo Brasil viveu foi comaConstituição de 1988, emboramuitas leis e decretos que deviam ter sido implementadas posteriormentenão o foram atéhoje. A década seguintedesarmou tal possibilidade.

O trabal ho, no Brasil, éregulado pela Consolidação das Leis Trabal histas (CLT), sistematizada em 1943, na qual estão estabel eci das as condições deutilização da força de trabal ho tai s como: jornada de trabal ho, regulamentação do trabal ho feminino edo menor, descanso, férias remuneradas, salário mínimo, etc.. Entretanto, só têmaces-

${ }^{12}$ A prática da "portage" se distingue nitidamente do ínterim, com o qual se compara às vezes, principalmente porque é o porté - e não a sociedade de portage - quem procede à procura dos clientes e negocia com eles, enquanto que a razão de ser da sociedade deínterim está na procura de missões para os interimarios inscritos em seu cadastro (http://www.guideduportage.com/ virtual egisl.htm).

${ }^{13} \mathrm{CDIs}$, CDDs, contratos de formação (contrato de aprendizagem, contrato de profissionalização), contratos de inserção (contrato de acompanhamento no emprego, contrato de inserção - Renda Mínima de Atividade [RMA], contrato de futuro), contrato Iniciativa Emprego (específico para públicos afastados do contrato de trabal ho "normal"), contratos que dependem dos Códigos civil ou comercial, etc.. 
so a esses direitos os trabal hadores que possuama carteira detrabal ho assinada pel o seu empregador. Estrutural mente, o mercado de trabal ho conviveu com $40 \%$ dos trabal hadores sem carteira assinada, ou seja, sem proteção legal, até os anos oitenta do século passado. Coma criseda dívida externaedo padrão definanciamento do desenvolvimento bra sileiro no início dos anos oitenta, esse percentual aumentou; agravou-se, em seguida, comaintrodução, nosanosnoventa, das práticas deflexi bilização dosmercados detrabal ho queacompanharamaagendamarcadapelaaberturacomercial, privatização das empresas públicas, desregulamentação dos mercadosfinanceiros esubmissão ao receituário emanado do Consenso de Washington.

A hibridização no caso brasileiro podeser ilustrada pel a ampliação da presença decontratos de trabal ho atípicos, entendidos como contratos que fogem do padrão de contratação por tempo indeterminado deum só patrão. Asformas atípicas mais usuais são: contratos por tempo determinado, contrato desafra, contrato por empreitada, contrato por experiência, estágio. Além disso, Krein (2007, p.105) chama a atenção para a necessidade de agregar a esses exempl os a facilidade de o empregador romper unilateral menteo contrato detrabalho, as ocorrências de relação de emprego disfarçadas pelacontratação depessoajurídicaindividual, ,14 a terceirização, a subcontratação eainda as cooperativas detrabal ho.

Em si, o caso brasileiro é emblemático de uma situação queaparentementenão mudou. Porém a observação da produção de leis e decretos, nesses últimos anos, revela que o marco legal foi al terado. Com efeito, aCLT permaneceu inalterada naletra, porémumasucessão de decretos-lei trans-

${ }^{14}$ Em junho de 2007, o Brasil vivia um novo risco de agravamento das condições de seu mercado de trabal ho que é a manutenção da emenda 3 - projeto de lei criando a Super Receita, órgão que agrega a Previdência Social ea Receita Federal. Essa emenda retira dos fiscais do Ministério do Trabalho o direito de verificar se há vínculo empregatício em uma relação de trabal ho considerada suspeita ou irregular. Constitui-se, então, na possibilidade da general ização de empresas individuais que prestarão serviços às grandes empresas, burlando, a um só tempo, a legislação trabal hista e os impostos devidos, reduzindo enfim, o fundo público. O presidente Lula vetou essa emenda, porém há o risco de esse veto ser anulado por votação no Congresso Nacional. formou o seu teor (Cacciamali, 2004). Assim, a efetiva flexibilização do mercado detrabal ho constitui ataques ao espírito original da lei, organizados através decinco tipos demudanças:

- novas modalidades de indenização quando da rescisão do contrato detrabal ho;

- flexibilização dajornada detrabal ho;

- flexibilização da remuneração;

- novas formas de resolução fora dos tribunais dos conflitos;

- reformasindical.

I gual menteao queocorrena França, os ataques ao contrato clássico de trabal ho, no Brasil, explicitam formasinstitucionais diferentes. A sua semel hançaévisível graças a uma anal ogia comas três unidades detempo, delugar e de ação do teatro clássico. O tempo édividido em diferentes arranjos (contratos por tempo determinado, temporários, por tempo parcial), ou há contratos que prevêemasua própriasuspensão temporária, além da Medida Provisória -MP - Banco de Horas, que promove a anualização do tempo de trabalho. $\mathrm{O}$ lugar não é mais automaticamente o do ateliêou da empresa: o trabal ho podese desenvolver dentro da empresa e (ou) em casa. A lém disso, a ação pode se desenvolver de diversos modos polivalência, realização de uma missão na sua integral idade, etc. Portanto, novas relações detrabal ho que derrogam a norma clássica acabam se instaurando: os "autônomos" permanecem autonômos somente em aparência, pois suas encomendas tendem a depender de um só contratante. Damesmaforma, a individualização darela ção sal arial, cadavez mais freqüente, faz com que o "holerite" dedois indivíduos da mesma empresa, comas mesmas competências, possa variar. A MP "Participação aos lucros e aos resultados"15 procedenamesmalógica, pois as gratificações não estão integradas de forma definitiva ao salário, o queisenta os trabal hadores epatrões dequal quer contribuição adicional à PrevidênciaSocial. Todas essas medidas concorrem para a flexibilização do

\footnotetext{
${ }^{15}$ Medida Provisória "Participação dos trabal hadores nos lucros ou resultados das empresas" no794, de 29 de de-
} zembro de 1994. 
contrato detrabal ho e para a precarização de seu titular (Azaïs, 2006).

\section{MERCADOS DE TRABALHO E HIBRIDIZAÇÃO}

Ao associarmos mercado de trabalho e hibridização, queremos dar concretudeao conjunto das medidas flexi bilizadoras já aplicadas nos diferentes mercados detrabal ho sob anál iseeprecisar as suas especificidades. Nesse sentido, qual é o formato dos mercados de trabal ho flexibilizados nos quais a hibridização já está presente?

\section{A uniformidade}

A uniformi dademais consistente, queaparece em diferentes mercados de trabalho, éa evidência clara do assalariamento como forma prevalentedeinserção nos mercados detrabal ho. A Tabela 4a evidencia o exemplo francês, no qual 89\% dos ocupados, em 2005, eram assalariados, condição maisimportanteentreas mulheres, 92,5\%, e86,2\% entreoshomens. Assim, otrabal ho autônomo ou por conta própria, mais osempregadores, não

Tabela 4(a) - França - Distribuição dos ocupados segundo o estatuto do emprego em 2005 (em \%)$$
\begin{array}{lcccc}
\hline & \text { Mulheres } & \text { Homens } & \text { Totais } \\
\hline \text { Emprego não assalariado } & 7,5 & 13,8 & 10,9 \\
\hline \text { Emprego assalariado } & 92,5 & 86,2 & 89,1 \\
\hline \text { Total } & 100,0 & 100,0 & 100,0 \\
\hline \text { Fonte: Concialdi (2006, p.21) - tradução e organização da tabela de }
\end{array}
$$
responsabilidade dos autores.

Tabela 4(b) - França - Distribuição do emprego assalariado e hibridização, ou seja, por diferentes condições contratuais, em 2005 (em \%)

\begin{tabular}{|c|c|c|c|}
\hline & Mulheres & Homens & Totais \\
\hline $\begin{array}{l}\text { Emprego assalariado estável } \\
\text { Contrato por tempo indeterminado - CDI por tempo integral }\end{array}$ & 55,4 & 71,9 & 64,4 \\
\hline $\begin{array}{l}\text { Emprego assalariado estável } \\
\text { Contrato por tempo indeterminado } \\
\text { CDI por tempo parcial }\end{array}$ & 23,8 & 3,0 & 12,6 \\
\hline Emprego assalariado com estatuto precário - Contrato por tempo determinado - CDD & 8,7 & 5,3 & 6,9 \\
\hline Emprego assalariado com estatuto precário - Trabalho intermitente & 1,4 & 2,8 & 2,2 \\
\hline Estagiários & 2,2 & 1,4 & 1,7 \\
\hline Aprendizes & 0,9 & 1,7 & 1,3 \\
\hline Totais relativos & 92,5 & 86,2 & 89,1 \\
\hline
\end{tabular}

ultrapassa a casa dos 10,9\%, ou seja, não há como esperar muito de uma solução para o desemprego francês pautado pelo empreendedorismo e pelotrabalho por contaprópria.

Considerando agora a Tabela 4b, fica evidente que, mesmo após 20 anos deflexibilização dos contratos detrabal ho, a hibridização do mercado de trabal ho francês permitequeainda $64,4 \%$ dos assal ariados tenham um contrato de trabal ho por tempo indeterminado, o CDI a tempo pleno. Entre os homens, essa partici pação chega a aproximadamente $72 \%$ dos assal ariados, enquanto, entre as mulheres, é de apenas 54\%. Logo, a hibridização atingemais negativamenteas mulheres. A esse grupo podemos associar, sem dúvida, os jovens. Assim é que, em 2006, a proposta do CPE - Contrat Première Embauche (Contrato Primeiro Emprego) - gerou uma enorme manifestação por todo o país, atéa retirada da proposta da Assembléia Nacional. Tampouco se podeesquecer a situação dos trabal hadores "idosos", isto é, acima dos 50 anos, cuja proporção no desemprego é elevada, o que dá uma feição particular ao mercado detrabal ho francês, poiselerepousa mais intensamente na população ativa compreendida entre os 30 e os 40 a 45 anos de idade.

A esse grupo se juntam os portadores do CDI por tempo parcial, eessas participações che gam a $12,6 \%$ para o conjunto dos assalariados, sendo $23,8 \%$ entreas mul hereseapenas 3,0\% entre os homens. Mesmo assim, é importante apontar para o fato deque $77 \%$ dos assal ariados franceses 
possuem um contrato por tempo indetermi nado.

O caso brasileiro éal go mais complexo, se comparado com o francês. Certamente o assalariamento é a forma prevalente de inserção nos mercados detrabal ho, pois $59,1 \%$ dos ocupados, em 2005, eram assalariados ou empregados, segundo a PNAD//BGE (Tabela 5). Mesmo em um patamar significantementemaisbaixo doqueo francês (89,1\% dos ocupados são assalariados), no Brasil, o assal ariamento também domina. É necessário destacar que, em 1995, o grau de assal ariamento do mercado detrabal ho brasileiro era de $55 \%$ dos ocupados, tendo tido um crescimento significativo nosúltimos dez anose, deforma particular, no período entre 2001 e2005. Essa éuma informação relevante para a compreensão da economia brasileira, pois, na década passada, havia uma interpretação dominante, entreal guns acadêmicos, a mídia e o empresariado, de que o crescimento da ocupação sefariamediantea ampliação do empreendedorismo, dos pequenos empregadores e dos trabal hadores autônomos. Ou seja, dado o processo degl obal ização ede reetruturação produtiva, cada um deveria ser o seu próprio patrão. Assim, esse desempenho recente tão exitoso do mercado detrabal ho evidencia, inegavel mente, a rel ação positiva entre crescimento econômico e assalariamento, inclusive, assalariamento formal, com registro em carteira.

No entanto, é fundamental esclarecer que esse patamar deassal ariamento não corresponde ao percentual detrabal hadores protegidos por alguma legislação. Para obter tal partici pação, agregamos os trabal hadores empregados com carteira de trabal ho assinada $(34,1 \%)$, o trabal hador doméstico com carteira (2,2\%), os funcionários públicos estatutários $(6,4 \%)$ e os militares $(0,3 \%)$. Assim, do conjunto dos ocupados em 2005, no Brasil, apenas $41 \%$ possuem proteção pelalegislação trabal hista, respeitando-se as diferenças que regem civis emilitares.

Paraumamel hor compreensão das diferenças entreos dois mundos, éimportanteconsiderar quetemosainda, entreosocupados, $5 \%$ quetrabaIha sem remuneração e 3\% produz apenas para o seu próprio consumo. Essas partici pações reduziram-senosúltimos dez anos, mas continuam significativas. Também merece destaquea grandeza da participação dos trabal hadores domésticos, queé de $8 \%$ do conjunto dos ocupados, em 2005.

A Tabela 5 também revela a significativa participação dos trabal hadores autônomos ou por

Tabela 5 - Brasil - Composição do mercado de trabalho por condição de ocupação e posição na ocupação $1995 / 2005$

\begin{tabular}{|c|c|c|c|c|}
\hline Composição do mercado de trabalho & $\begin{array}{c}\text { \% sobre população } \\
\text { ocupada } 1995\end{array}$ & $\begin{array}{l}\text { \% sobre população } \\
\text { ocupada } 1999\end{array}$ & $\begin{array}{c}\text { \% sobre } \\
\text { população } \\
\text { ocupada } \mathbf{2 0 0 2}\end{array}$ & $\begin{array}{c}\text { \% sobre } \\
\text { populaçáo } \\
\text { ocupada } \mathbf{2 0 0 5}\end{array}$ \\
\hline População ocupada total (PO) & 100,0 & 100,0 & 100,0 & 100,0 \\
\hline Empregado assalariado total & 55,0 & 55,2 & 57,7 & 59,1 \\
\hline Assalariado com carteira & 31,4 & 30,2 & 32,0 & 34,1 \\
\hline Assalariado sem carteira & 16,2 & 17,7 & 18,7 & 18,3 \\
\hline Militar & 0,5 & 0,4 & 0,4 & 0,3 \\
\hline Funcionário público estatutário & 6,9 & 6,8 & 7,6 & 6,4 \\
\hline Trabalho doméstico total & 7,4 & 7,7 & 8,0 & 8,0 \\
\hline Doméstico com carteira & 1,6 & 2,0 & 2,2 & 2,2 \\
\hline Doméstico sem carteira & 5,9 & 5,7 & 5,8 & 5,8 \\
\hline Trabalhador por conta própria não-agrícola & 16,7 & 17,3 & 17,0 & 16,4 \\
\hline Trabalhador por conta própria agrícola & 5,9 & 5,5 & 4,7 & 4,2 \\
\hline Empregador & 4,1 & 4,1 & 4,1 & 4,1 \\
\hline Trabalhador não remunerado & 7,2 & 6,9 & 5,7 & 5,0 \\
\hline Trabalhador produção consumo próprio & 3,6 & 3,2 & 2,7 & 3,0 \\
\hline Trabalhador construção uso próprio & 0,0 & 0,1 & 0,2 & 0,1 \\
\hline
\end{tabular}

Elaboração: DISOC/IPEA. Obs. Está incluída a população de 16 a 59 anos de idade; os cálculos excluíram as pessoas da zona Norte rural. 
conta própria de $20,6 \%$ dos ocupados, o que re presenta praticamenteo dobro da partici pação relativa da categoria na França. Em trabal ho anterior, Carleial (2000) já havia formulado a hipótese de quea mai or presença detrabal hadores autônomos éum indicador desubdesenvolvimento e, evidentemente, da baixa partici pação de investimentos produtivosimportantes, quegerem dinamicamente novos postos de trabal ho.

A prevalênciado assalariamento eo crescimento da participação dos assalariados formais constituemfatosmarcantes do desempenho recente do mercado de trabal ho brasileiro. Krein, Moretto (2005) consideram que a ampliação do emprego formal deve-se ao crescimento econômi co ainda modesto, mas efetivo, eà ampliação da fiscal ização das empresas pelajustiça do Trabal ho, especial mente responsabilizando as empresas-mãe pelos empregados desuas empresas subcontratadas.

Quanto àsformas decontratação atípicas no Brasil, Krein (2007, p.109) consideraqueelas ainda são pouco expressivas. Utilizando dados daRAIS/ TEM, o autor evidencia que elas correspondiam a apenas 5,9\% dosempregos formais ativos no país. Emnúmeros absolutos, existiam apenas dois miIhões deempregados efuncionários públicos regidos por al guma forma de contratação atípica. Entretanto, no período de 1995 a 2005, essa forma de contratação cresceu $158,6 \%$, percentagem bemsuperior, comparativamente, àquela do crescimento da contratação por tempo indeterminado, quefoi de $38,8 \%$. O autor argumenta ainda que essa formadecontratação ampliaa precariedadeno trabaIho, pois os salários pagos são bem mais baixos, em média, do que os pagos para os demais tipos detrabalhadores.

\section{As diferenças}

A análise precedente, na qual se buscou evidenciar queexistem semelhanças nos efeitos da gl obal ização sobre os mercados de trabal hos no NorteenoSul, mais precisamenteentreFrançae Brasil, éfortementecondicionada pel as diferenças histórico-estruturais entreesses mundos. A construção inconclusa de uma sociedade salarial no Brasil nos impededeanal isála sob a égidedo processo demercantilização, desmercantilização eremercantilização da força detrabal ho, quemarcou e marca a conformação dos mercados de trabal ho europeus, deu concretude à constituição desuas democracias enorteou a sua regulação macro-econômica. Mesmo sujeito à gl obalização, o Estado-

Providênciaeuropeu continua "firmeeforte", como evidenciam Taylor-Gooby (2004) eClarke(2004), tendo sido capaz deincluir formas diferenciadas deatendimento aos "novos riscos" sociais, decorrentes exatamentedosmecanismos dehi bridização dos contratos detrabalho.

Não ésem razão, por exemplo, quefoi exa tamente nos países-berço da social-democracia européia, nos quais a associação entre ação sindical, partidos deesquerda egastos sociais foi mais intensa, que emergiu a "flexisécurité" (ou "flexicurité"), que se constitui numa proposição diferenciada de divisão de riscos entre o indivíduo e o coletivo, comparativamente ao auge dos anos dourados, mas que mantém, seguramente, uma proposição de proteção aos trabal hadores.

A flexicuridadeaparenta ser uma "estraté gia política que tenta, de maneira del iberada, reforçar aflexibilidadedos mercados detrabal ho, da organização do trabal ho edas relações detrabal ho, por um lado, e, por outro, manter a segurança segurança deemprego ePrevidência social - principalmente para os grupos em dificuldade no e fora do mercado detrabal ho" (Tangian, 2005, p.10). A flexicuridaderemeteà idéia deuma compensação da desregul ação do mercado de trabal ho por medi das desegurança de emprego eda Previdência (Tangian, 2005), dequetambém tratam diversos relatórios da OCDE (2002) ou de Eurostat (2004), quando apontam para os efeitos da desregulação rel ativos ao trabal ho.

Esse debate lembra aquele do aumento da insegurança no trabal ho dessas úl timas duas dé cadas e a discussão sobre e emergência de "novos riscos sociais", vincul ados à hibridização do mercado detrabal ho. Asrazões do surgimento de"no- 
vos riscos sociais" residem na desi ndustrial ização ena externalização dos empregos, no aumento da participação das mulheres no mercado de trabaIho, na instabilidade crescente das estruturas familiares e na "desestandardização" do emprego. Todas essas manifestações, perceptíveis na proliferação das formas de inserção no trabal ho e dos contratos de trabal ho, acompanham taxas de desemprego el evadas, características próprias à sociedadepós-industrial (Bonoli, 2005).

O estágio dessa discussão no Brasil épraticamenteinexistente, pois o eixo mercado detrabaIho e proteção social careceainda de mai or sedimentação. Entretanto, fica evidentepela discussão empreendida atéaqui, a tendência de fragmentação da legisl ação de proteção ao trabal ho eo afastamento da "norma clássica" que rege os mercados detrabal ho no Nortee no Sul.

Finalmente, quando seanal isamas perspectivas demercado de trabal ho, as di ferenças ficam ainda mais gritantes. Bastariarelembrar as diferenças de patamar básico de educação entreas duas sociedades, a posição subordinada na fronteira tecnológicano caso brasileiro eainda a eficácia do avanço do capitalismo financeiro, retratadonamaior taxa dejuros real do mundo. Entretanto podemos ir além. O Brasil passa por um significativo processo de desindustrialização precoce, decorrente dos processos de fusão e aquisição desencadeados nos anos noventa do sécul o passado, da venda das empresas estatais produtivas e dainstauração de firma-redes poderosas, ligadas aos mais importantes setores da indústria. Essa desindustrialização é demonstrada pela redução da partici pação do produto industrial no PIB brasileiro, mas, principalmente, pela perda de elos importantes das cadeias industriais. ${ }^{16}$ A UNCTAD denunciou, em 2003, esse processo eo intitulou de "desindustrial ização negativa". ${ }^{17}$ Entretanto,

${ }^{16}$ De fato, a queda da participação do produto industrial no PIB começou nos anos oitenta; de uma participação de $32,1 \%$ do PIB, em 1985, ela passa para $19,1 \%$, em 1998. A partir de 1999, com a desvalorização do real, essa participação volta a aumentar e, atual mente, ela é de $23 \%$ do PIB.

17 O "patriotismo econômico" é um conceito difícil de precisar. No entanto, com a ajuda de uma publicação coletiva do Le cercle des économistes (2006, p.126), po-
Carneiro (2003) já havia remarcado a redução da diversidadeindustrial brasileira; Carleial (2004), por suavez, nomeou esse processo de "subdesenvolvimento gl obalizado", eo IEDI (2005) indicou uma "desindustrialização relativa", chamando a atenção sobre os efeitos negativos desse quadro sobre o dinamismo econômico do país.

Ademais, o Brasil ocupa um papel subordinado na divisão internacional do trabal ho na indústria, concentrando os investimentos das atividades de montagem, como no caso do setor automotivo. Essetipo dedesindustrial ização tem implicações viol entas sobre o mercado de trabaIho, porque, se o Brasil tem uma indústria com baixacapacidadedesediar projetos edesenvolver produtos, ele não tem como qual ificar os postos detrabal hos, mel horar a estrutura salarial ea formação profissional dos engenheiros, químicos, técnicosem geral.

Finalmente, ébomlembrar quea recente(junho de2007) reunião do G8, naAlemanha, napresença do G5, deixa muito claro oabismo quesepara os dois gruposeas dificuldades crescentes deconsol idação dos seus mercados de trabal ho, expressas nas três principais recomendações: os subdesenvolvidos precisariam abrir mais ainda as suas fronteiras parao investimento produtivo internacional; os desenvol vidos precisam criar um sistema maisrigoroso decontrol edas patentese, ainda, neste momento, ossubdesenvol vidos precisam controlar as suas emissões de poluentes na atmosfera.

Tudo isso nos leva a concluir que, mesmo dianteda prevalência doassalariamento como formadeinserção nos mercados detrabal ho do Norte edo Sul, da presença dehibridização emseus mercados de trabalho, é instransponível, em curto e médio prazos, a diferençaexistentenos mundosdo trabalhobrasileiro efrancês, oquedesqualificaqual-

demos considerar que o "patriotismo econômico" revela que "o coração de uma empresa bate ao ritmo do país no qual seu estado-maior e suas funções mais sensíveis em particular, hoje, onde os centros de pesquisas estão instal ados". Os autores consideram que, mesmo diante das empresas mundiais, a nacional idade de cada empre sa perdura. "Ela está li gada fundamental mente à cul tura de seus principais dirigentes que têm a tendência de privilegiar seus países para o desenvolvimento das atividades de pesquisas, financeiras e de marketing." (tradução dos autores). 
quer tentativa de proposição de "brasilinização" do Norte.

Recebido para publicação em setembro de 2007) (Aceito em novembro de 2007)

\section{REFERÊNCIAS}

AMIN, S. Le développement inégal-essai sur les formations sociales du capitalisme périphérique. Paris: Editions de Minuit, 1973.

AZAIIS, C. Dé-segmentation du marché du travail et autonomie. In: BOUTILLIER, S.; UZUNIDIS, D. (Dir.) Travailler au 21 ème siècle, nouveaux modes d'organisation industrielle et spatiale du travail. Paris: De Boeck Université, 2006. p.113-127. (Collection economie, société, region).

Formes de travail, hybridation et dynamique territoriale. Revue d'Economie Régionale et Urbaine, Paris: ADICUEER, 2003/3, p.379-394.

BARBIER, J.C. A survey of the use of the term précarité in French economics and sociology. Paris: Centre d'Etudes de I'Emploi, nov., 2002. (Document de travail, n.19)

BONOLI, G. Time matters - postindustrialisation, new social risks and Welfare State adaptation in advanced industrial democracies, paper presented at the In: CONGRES DES QUATRE PAYS, 17-18 nov., 2005. Lausanne (Suisse): Université de Lausanne, 2005.

BORON, A. Estado, capitalismo y democracia en América Latina. Buenos Aires: CLACSO, 2004.

CACCIAMALI, M.C. Régime d'accumulation et processus d'informalité: le Brésil et le Mexique à l'unisson de I'Amérique Latine. In: LAUTIER, B.; MARQUES-PEREIRA, J. (Dir.), Brésil, Mexique deux trajectoires dans la mondialisation. Paris: Karthala, 2004. p.201-224.

CARDOSO, F.H.; FALETTO, E. Dependência e desenvolvimento na América latina. Rio de Janeiro: Zahar, 1970.

CARLEIAL, L. The Brazilian Labour Market: structural features, 'new' flexibilization and recent performance. In: CONGRESO DE LA ASOCIACIÓN LATINOAMERICANA DE SOCIOLOGÍA (ALAS), 25, 22 26 ago., 2005. Porto Alegre: UFRGS/IFCH/ PPG Sociologia, 2005.

Subdesenvolvimento globalizado: a resultante das escol has de política econômica nos anos noventa. Revista Paranaense de Desenvolvimento. Curitiba, IPARDES, n.106, p.7-28, 2004.

Assalariamento: conceitos, dimensões e "pistas" para entender a crise. In: ENCONTRO NACIONAL DA SOCIEDADE DE ECONOMIA POLITICA-SEP, 5, jun. Fortaleza, 2000. CD-Rom.

Ciência econômica e trabalho. In: ENCONTRO ANUAL DA ANPEC, 20, 1992, Campos do Jordão(SP), Anais... São Paulo: ANPÉC, 1992. p.15-26.

CARNEIRO, R. Desenvolvimento em crise. A economia brasileira no último quarto do século XX. São Paulo: Ed. UNESP/UNICAMP, 2003.

CASTEL, R. L'insécurité sociale -qu'est-ce qu'être protégé? Paris: Seuil/La République des Idées, 2003.

Métamorphoses de la question sociale. Une chronique du salariat. Paris: Fayard, 1995.

CLARKE, J. Changing welfare, changing states. New directions in social policy. London: Sage, 2004.

CONCIALDI, P. La France précarisée : un état de lieu In : HUSSON, M. (Dir.) Travail flexible, salariés jetables. Fausses questions et vrais enjeux de la lutte contre le chômage. Paris: La Découverte, 2006. p.17-27.

Eurostat. Eurostat databases: new chronos. Luxemburg: European Communities, 2004. Disponível em : www.europa.eu.int/comm/eurostat

GUIMARÃES, N.A. La "brésilianisation" de l'occident. Revue Tiers Monde: Argentine, Brésil: sorties de crise? Paris, n.189, p.155-174, 2007.

HALL, P.A.; SOSKICE D. (Eds.) An introduction to varieties of capitalism. In: Varieties of capitalism: the Institutional Foundations of comparative advantage. Oxford:Oxford University Press, 2001. p.1-68.

IEDI. Instituto de Estudos para o Desenvolvimento Industrial. Ocorreu uma desindustrialização no Brasil? nov., 2005. 31 p. Disponível em: www.iedi.org.br.

IRES. Les mutations de l'emploi en France. Paris: La Découverte, 2005. (Coll. repères)

KREIN, J.D. Tendências recentes nas relações de emprego no Brasil 1990-2005. 2007. Tese (Doutorado) - UNICAMP, Campinas(SP).

KREIN, J.D.; MORETTO, A. O crescimento da formalização do emprego: como explicá-lo? Campinas(SP): Unicamp, 2005. Mimeo.

LE BOUCHER, E. La grande revanche desenvolvimento pays du Sud. Le Monde, Paris, n.23/24 p.26 sept., 2007.

LE CERCLE DES ÉCONOMISTES. Politique économique de droite; politique économique de gauche. Paris: Perrin, 2006.

LIMA, J.C. O trabal ho em cooperativas de produção industrial: a volta de um vel ho paradigma. Revista Brasileira de Ciências Sociais, São Paulo, v.19, n.56, p.44-62, 2004

. As artimanhas da flexibilização: o trabalho em cooperativas de produção industrial. São Paulo: Terceira Margem, 2002.

OCDE. Organização para Cooperação e Desenvolvimento Econômico. Employment outlook. Paris: 2002.

OLIVEIRA, F. de As contradições do ão. São Paulo:, USP, 2005. Mimeo.

O surgimento do anti-valor. Capital, forca-de-trabalho e fundo público. Novos Estudos Cebrap. São Paulo, n.22, p.8-28, 1988.

PALLOIX, Ch. Industrialisation, désindustrialisation et formes de mise au travail. Revue Tiers-M onde, Paris, n.110, p.287-302, avril./juin., 1987.

PLIHON D. Précarité et flexibilité du travail, avatars de la mondialisation du capital. In: HUSSON, M. (Dir.) Travail flexible, salariés jetables. Fausses questions et vrais enjeux de la lutte contre le chômage. Paris: La Découverte, 2006. p.123-133.

RAMAUX, Ch. 'Sécurité sociale professionnelle' ou 'sécurité emploi-formation': I'enfer est pavé de bonnes intentions. In: ROUEN, LISE/GRIS/ JOURNÉES INTERNATIONALE DE SOCIOLOGIE DU TRAVAIL, RELATIONS AU TRAVAIL, RELATIONS DE TRAVAIL, 10, London, 2005. v.3, p.591-604.

ROCHA, S.; CAVALCANTI, R. A questão do emprego no Brasil (1996-2004). Rio de Janeiro: IETS, 2006. Disponível em: www.iets.org.br. 
TANGIAN, A.S. Monitoring flexicurity policies in the EU with dedicate composite indicators, pal estra na DG. In: EUROPEAN COMMISSION. Employment, social affairs and equal opportunities. Brusseles: june, 2005. (Diskussionpapier n.137)

TAYLOR-GOOBY, P (Org.) New Risks, New Welfare. The transformation of the European Welfare State. New York: Oxford University Press, 2004.
UNCTAD. Trade and Development Report, 2003. Disponível em: www.unctad.org

VERGARA, F. Les dessous du plein-emploi américain. In: HUSSON, M. (Dir.) Travail flexible, salariés jetables. Fausses questions et vrais enjeux de la lutte contre le chômage. Paris: La Découverte, 2006. p.88-100. 
MERCADOS DE TRABALHO E HIBRIDIZAÇÃO: uniformidade e diferenças França/Brasil

\section{Liana Carleial} Christian Azaïs

Este artigo se propõe a problematizar interpretações recentes que admitem um processo de "brazilinização" do Norte, a partir das tendências dos mercados de trabalho. No centro da nossa discussão está o conceito de hibridização, enquanto categoria capaz de capturar as diferentes formas de flexibilização vivenciadas pelos mercados de trabalho e construir uma comparação sobre o desempenho recente dos mercados de trabalho na França e no Brasil. O artigo está estruturado em cinco passos. No primeiro deles, fazemos uma análise da natureza da globalização; num segundo, discutimos a especificidade do mercado de trabalho bem como as condições sócio-políticas de sua regulação em cada uma das realidades em análise; no terceiro, introduzimos o conceito de hibridização que captura os efeitos da flexibilização e da precarização d(n)os mercados de trabalho. No quarto, associamos mercados de trabalho e hibridização para evidenciarmos que a uniformidade de mercado de trabalho que existe entre o Norte e o Sul, ou mais precisamente, entre a França e o Brasil, é configurada pela wa prevalência do assalariamento como forma dominante de inserção nos mercados de trabalho; no entanto, a hibridização nos mercados de trabalho na França e no Brasil é de

PALAVRAS-CHAVE: globalização, mercado de trabalho, hibridização, assalariamento.
JOB MARKETS AND HIBRIDIZATION: uniformity and differences between France and Brazil

\section{Liana Carleial} Christian Azaïs

This paper intends to problematize recent interpretations that admit a process "brazilinization" of the North, starting admettent le fait d'un processus de from the tendencies of the job markets. In "brasilisation" du Nord, en partant des the center of our discussion is the tendances des marchés du travail. Le point hibridization concept, as a category central de l'exposé est le concept d'une capable of capturing the different ways of hybridation considérée comme une catégorie flexibilization endured by the job markets capable d'appréhender les différentes formes and to build a comparison on the recent de flexibilité vécues par les marchés du travail performance of the job markets in Brazil et d'élaborer une comparaison avec le and France. This paper is structured in five développement récent des marchés du travail steps. In the first of them, we make an en France et au Brésil. L'article comprend analysis of the nature of globalization; in cinq étapes. D’abord nous ferons une analyse the second, we discuss the specificity of de la nature de la globalisation; nous parlerons the job market as well as the social and ensuite de la spécificité du marché du travail political conditions of its regulation in ainsi que des conditions socio-politiques de sa each of the realities in analysis; in the réglementation, dans chacune des réalités hird, we introduce the hibridization analysées; dans la troisième étape, nous concept that captures the effects of introduirons le concept d'hybridation qui flexibilization and of the precarization of appréhende les effets de la flexibilité et de la the job market or markets. In the fourth, précarité des marchés ou sur les marchés du we associate job markets and hibridization travail. Dans la quatrième partie, un parallèle to evidence that the job market uniformity est fait entre les marchés du travail et that exists between North and South, or l'hybridation en vue de faire remarquer que more precisely, between France and Brazil, l'uniformité du marché du travail qui existe is configured by the prevalence of the entre le Nord et le Sud, ou plus pré-cisément wages as the dominant form of insertion entre la France et le Brésil, est due au fait que in the job markets; however, the les salaires constituent la forme dominante hibridization in the job markets in France de l'insertion sur les marchés du travail. and in Brazil is of different nature, volume Cependant l'hybridation au sein des marchés and consequences.

KEYwords: globalization, job market, hibridization, wage. du travail, en France et au Brésil, a une nature, un volume et des conséquences distincts.

Mots-CLÉs: globalisation, marché du travail, hybridation, salaires. 